\title{
EVALUASI KARAKTERISTIK KUANTITATIF KAMBING SAMOSIR BERDASARKAN ANALISIS KOMPONEN UTAMA DI KECAMATAN NAINGGOLAN KABUPATEN SAMOSIR
}

\section{Evaluation of Quantitative Characteristics of Samosir Goats Based on Principal Componen Analysis in Nainggolan District Samosir Regency}

Petrisa P. Damanik, Eko Wiyanto, Depison*

Department of Animal Husbandry, Faculty of Animal Husbandry, University of Jambi

Jl. Jambi-Ma. Bulian KM 15 Mendalo Darat Jambi 36361

*E-mail : depison.nasution@unja.ac.id

Submitted : May 15, $2020 \quad$ Accepted : July 19, 2020

\begin{abstract}
ABSTRAK
Penelitian ini bertujuan untuk mengetahui karakteristik kuantitatif kambing Samosir jantan dan betina di Kabupaten Samosir Kecamatan Nainggolan. Metode yang digunakan dalam penelitian ini adalah metode observasi. Teknik pengambilan sampel secara purpossive sampling yaitu umur 6-12 bulan, tidak dalam keadaan bunting, dengan jumlah sampel sebanyak 60 ekor yang terdiri dari 30 ekor jantan dan 30 ekor betina. Data yang dihimpun adalah karakteristik kuantitatif meliputi: bobot badan, pertambahan bobot badan, panjang badan, tinggi pundak, lingkar dada, dalam dada, lebar dada, tinggi pinggul, lingkar kanon dan lingkar scrotum kambing samosir di Kabupaten Samosir. Data yang telah dikumpulkan dianalisis menggunakan uji beda rata-rata (uji-T). Vektor nilai rata-rata ukuran-ukuran tubuh Kambing Samosir dianalisis menggunakan uji statistik $T^{2}$-Hotelling, selanjutnya analisis komponen utama digunakan untuk mengidentifikasi penciri bentuk dan ukuran tubuh pada ternak kambing. Pengolahan data dibantu dengan menggunakan perangkat lunak statistik Minitab 18. Hasil penelitian menunjukkan bahwa bobot badan dan pertambahan bobot badan kambing Samosir jantan lebih baik dibandingkan kambing Samosir betina. Faktor penentu ukuran tubuh adalah panjang badan sedangkan faktor penentu bentuk tubuh adalah lebar dada.
\end{abstract}

Kata kunci : Karakteristik kuantitatif, Analisis komponen utama, Kambing Samosir.

\section{ABSTRACT}

This research of this study aimed to know the quantitative characteristics of male and female Samosir goats in Nainggolan District, Samosir Regency. The method used in this research was an observation method. The sampling technique was purposive sampling, namely 6-12 months of age, not pregnant, with 60 samples consisting of 30 males and 30 females. The data collected were quantitative characteristics including: body weight, body weight gain, body length, shoulder height, chest circumference, chest width, hip height, canon circumference and scrotum circumference of Samosir goats in Samosir Regency. Data collected were analyzed using the average difference test (t-test). Vector value of the average body measurements of Samosir goats were analyzed using the $T^{2}$-Hotelling statistical test, furthermore, analysis of the main components was used to identify the markers of body shape and size in goats. Data analysis was assisted by using Minitab 18 statistical software. Results showed that the body weight and body weight gain of male Samosir goats were better than those of female Samosir goats. The determining factor for the body size was body length while the determining factor for the body shape was Chest Width.

Keywords: Principal componen analysis, Quantitative characteristics, Samosir goats 


\section{PENDAHULUAN}

Ternak kambing merupakan ternak ruminansia kecil yang memiliki prospek pengembangan yang cukup baik dalam menyuplai kebutuhan daging, pupuk maupun bulu. Ternak kambing cukup digemari masyarakat karena sistem pemeliharaannya masih secara tradisional dan memiliki adaptasi yang baik. Di Indonesia pelestarian dan pengelompokan ternak menurut bangsa kambing dapat dimulai dengan sebutan khusus menurut wilayah, misalnya Marica di Sulawesi Selatan, Benggala di Nusa Tenggara Barat, Muara di Sumatera Utara, Jawarandu di Jawa Tengah, Gembrong di Bali, kambing Samosir di Sumatera Utara, dan jenis lainnya di daerah Indonesia (Ginting et al., 2017). Salah satu kambing lokal yang memiliki potensi untuk dikembangkan adalah kambing Samosir.

Kambing Samosir merupakan kambing lokal yang terdapat di daerah kabupaten Samosir, Sumatera Utara. Kabupaten Samosir memiliki potensi pengembangan ternak yang cukup besar, dimana sektor peternakan di daerah tersebut meliputi peternakan sapi, kerbau, dan kambing. Populasi ternak kambing di kabupaten Samosir mencapai 9.821 ekor (Hanafi et al., 2017). Berdasarkan sejarahnya, kambing ini dipelihara penduduk setempat secara turun temurun di Pulau Samosir, ditengah Danau Toba, Kabupaten Samosir, Provinsi Sumatera Utara.

Upaya yang dapat dilakukan dalam rangka pelestarian plasma nutfah kambing Samosir adalah dengan mengumpulkan data dasar berupa karakteristik kuantitatif dalam populasi dengan cara melakukan karakterisasi. Karakterisasi merupakan kegiatan dalam rangka mengidentifikasi sifat-sifat penting yang bernilai ekonomis atau merupakan penciri rumpun yang bersangkutan. Tujuan dari karakterisasi adalah untuk mendapatkan data sifat atau deskripsi morfologi dari ternak kambing yang bertujuan untuk mengetahui fenotipe dan seberapa besar keragaman genetik yang dimiliki pada wilayah tersebut (Nurfaizin and Matitaputty, 2017). Salah satu tujuan analisis kuantitatif adalah untuk menentukan hubungan antar variabel dalam sebuah populasi.

Karakteristik kuantitatif merupakan karakteristik ternak yang tampak dari luar dan dapat digambarkan melalui : bobot badan (BB), panjang badan (PB), tinggi pundak (TP), lingkar dada (LiD), dalam dada (DaD), lebar dada (LeD), tinggi pinggul (Tpi), lingkar kanon (LK) dan lingkar scrotum (LS). Hingga saat ini, kegiatan karakterisasi fenotif ternak kambing Samosir belum banyak dilakukan di kabupaten Samosir.
Padahal karakterisasi ini menjadi dasar yang sangat penting untuk mengetahui struktur populasi, rencana konservasi yang efektif dan pemanfaatan sumber daya genetik dimasa yang akan datang. Berdasarkan uraian diatas maka perlu dilakukan penelitian tentang evaluasi karakteristik kuantitatif kambing Samosir berdasarkan analisis komponen utama di kecamatan Nainggolan kabupaten Samosir.

\section{MATERI DAN METODE}

\section{Materi \\ Penelitian ini dilaksanakan dari tanggal 15 Juli sampai tanggal 04 September 2019 di Kecamatan Nainggolan, Kabupaten Samosir Sumatera Utara. Materi yang digunakan pada penelitian ini adalah kambing Samosir jantan dan betina sebanyak 60 ekor. Peralatan yang digunakan adalah alat tulis, tongkat ukur, pita ukur, timbangan digital dan kamera.}

\section{Metode}

Metode yang digunakan dalam penelitian ini adalah observasi. Teknik pengambilan sampel dilakukan secara purpossive sampling dan kambing yang akan diteliti tidak dalam keadaan bunting, dengan jumlah sampel sebanyak 60 ekor dengan umur $\mathrm{I}_{0}$ (6-12 bulan) 30 ekor jantan dan 30 ekor betina. Data yang telah dikumpulkan meliputi: BB, PB, TP, LiD, DaD, LeD, TPi, LK dan LS kemudian dikelompokkan berdasarkan jenis kelamin yaitu jantan dan betina, selanjutnya dianalisis dengan menggunakan uji t (Gaspersz, 2006). Vektor nilai rata-rata ukuran-ukuran tubuh kambing Samosir dianalisis menggunakan uji statistik $\quad \mathrm{T}^{2}$-Hotelling (Gespersz, 2006), selanjutnya Analisis Komponen Utama (AKU) digunakan untuk mengidentifikasi penciri bentuk dan ukuran tubuh pada ternak Kambing Samosir. Pengolahan data dibantu dengan menggunakan perangkat lunak statistik Minitab 18.

\section{HASIL DAN PEMBAHASAN}

\section{Karakteristik Kuantitatif Kambing Samosir}

Karakteristik kuantitatif meliputi bobot badan, pertambahan bobot badan dan ukuran ukuran tubuh kambing Samosir jantan dan betina umur $\mathrm{I}_{0}$ (6-12 bulan) disajikan pada Tabel 1 . Berdasarkan Tabel 1 hasil penelitian rataan bobot badan kambing Samosir jantan dan betina lebih rendah jika dibandingkan dengan kambing lokal di Indonesia seperti kambing Kacang betina sebesar 14,48 kg, kambing jawarandu jantan 25,58 kg pada umur yang sama (Putri et al., 2014; Mardhianna et al., 2015). Hal ini berarti bahwa 
bobot badan kambing Samosir relatif lebih rendah jika dibandingkan dengan kambing lokal lainnya. Adanya perbedaan tersebut disebabkan bangsa ternak yang berbeda, sistem pemeliharaan yang berbeda dan lingkungan yang berbeda menjadi salah satu faktor yang mempengaruhi pertumbuhan ternak (Socheh et al., 2018).

Hasil penelitian pertambahan bobot badan harian kambing Samosir jantan dan betina lebih rendah dibandingkan penelitian Murdjito et al. (2011) yang menyatakan bahwa pertambahan bobot badan harian kambing Bligon jantan dan betina umur 6-12 bulan secara berurutan yaitu 0,15 dan $0,16 \mathrm{~kg}$. Rendahnya bobot badan dan pertambahan bobot badan kambing Samosir jantan dan betina dibanding kambing lainnya diduga karena adanya perbedaan faktor genetik dan manjemen pemeliharaan. Hal ini didukung dengan pendapat Gunawan et al. (2008) selain disebabkan karena faktor genetik perbedaan ukuran-ukuran tubuh yang terjadi disebabkan perbedaan lingkungan diantaranya manajemen pemeliharaan.

Hasil analisis uji beda rata-rata menunjukkan bahwa bobot badan, pertambahan bobot badan dan ukuran-ukuran tubuh kambing Samosir jantan dan betina berbeda nyata $(\mathrm{P} \leq 0,05)$. Perbedaan antara bobot badan, pertambahan bobot badan dan ukuran ukuran tubuh ternak kambing Samosir jantan dan betina diduga karena adanya pengaruh hormone jenis kelamin. Hal ini sesuai dengan pendapat Setiyono et al. (2017) bahwa hormone testosteron atau androgen merupakan suatu hormon steroid yang dihasilkan oleh testis yang menyebabkan pertumbuhan ternak jantan lebih cepat dibandingkan betina.

\section{Statistik $\mathbf{T}^{2}$-Hotelling Kambing Samosir jantan dan betina}

Hasil uji $\mathrm{T}^{2}$-Hotelling pada ukuran-ukuran tubuh kambing Samosir jantan dan betina yaitu 169,32 dengan Nilai F Hitung 22,52. Hasil analisis $\mathrm{T}^{2}$-Hotelling Kambing Samosir jantan dan betina meliputi PB, TP, LiD, DaD, LeD, Tpi dan $L K$ berbeda sangat nyata $(P \leq 0,01)$. Perbedaan ini diduga karena adanya perbedaan jenis kelamin kambing Samosir. Menurut Soeparno (2005) bahwa ternak jantan lebih cepat tumbuh dibandingkan betina pada umur yang sama. Jantan memiliki testosteron salah satu steroid androgen, hormon pengatur pertumbuhan yang dihasilkan sel-sel interstistial dan kelenjar adrenal. Testosteron dihasilkan testis pada jantan, sehingga pertumbuhan ternak jantan dibandingkan betina lebih cepat.

Tabel 1. Bobot badan, pertambahan bobot badan dan ukuran-ukuran tubuh Kambing Samosir jantan dan betina di Kecamatan Nainggolan, Kabupaten Samosir. Body weight, weight gain and body measurements of male and female Samosir Goats in Nainggolan District, Samosir Regency

\begin{tabular}{|c|c|c|c|}
\hline $\begin{array}{c}\text { Uraian } \\
\text { Description }\end{array}$ & $\begin{array}{c}\text { Satuan } \\
\text { Unit }\end{array}$ & $\begin{array}{l}\text { Kambing Jantan } \\
\text { Male Goats }\end{array}$ & $\begin{array}{l}\text { Kambing Betina } \\
\text { Female Goats }\end{array}$ \\
\hline Bobot Badan/Body Weight (BB) & $\mathrm{kg}$ & $9,04 \pm 1,03^{\mathrm{a}}$ & $6,88 \pm 0,80^{\mathrm{b}}$ \\
\hline $\begin{array}{l}\text { Pertambahan Bobot Badan/Body Weight Gain } \\
\text { (PBB) }\end{array}$ & g/ekor/hari & $0,024 \pm 0,003^{\mathrm{a}}$ & $0,019 \pm 0,0038^{b}$ \\
\hline Panjang Badan/Body Length (PB) & $\mathrm{cm}$ & $43,59 \pm 1,48^{a}$ & $42,13 \pm 0,77^{b}$ \\
\hline Tinggi Pundak/Shoulder Height (TP) & $\mathrm{cm}$ & $38,32 \pm 0,78^{a}$ & $37,30 \pm 0,72^{b}$ \\
\hline Lingkar Dada/Chest size (LiD) & $\mathrm{cm}$ & $42,13 \pm 0,81^{\mathrm{a}}$ & $41,38 \pm 0,68^{b}$ \\
\hline Dalam Dada/Chest Depth (DaD) & $\mathrm{cm}$ & $20,67 \pm 0,73^{a}$ & $19,31 \pm 0,71^{b}$ \\
\hline Lebar Dada/Chest Width (LeD) & $\mathrm{cm}$ & $11,41 \pm 0,96^{\mathrm{a}}$ & $10,17 \pm 0,79^{b}$ \\
\hline Tinggi Pinggul/Hip Height (TPi) & $\mathrm{cm}$ & $39,75 \pm 1,64^{\mathrm{a}}$ & $36,36 \pm 0,66^{b}$ \\
\hline Lingkar Kanon/Ring Circumference (LK) & $\mathrm{cm}$ & $6,51 \pm 0,69^{a}$ & $6,10 \pm 0,31^{b}$ \\
\hline Lingkar Scrotum/Scrotum circumference (LS) & $\mathrm{cm}$ & $15,05 \pm 1,19$ & - \\
\hline
\end{tabular}

Keterangan: Huruf yang berbeda pada baris yang sama pada kolom berbeda menunjukkan perbedaan nyata $(\mathrm{P} \leq 0,05)$. Different letters in the same row in different columns show significant differences $(P \leq 0.05)$.

\section{Karakteristik Kuantitatif Penentu Penciri Ukuran dan Penciri Bentuk Tubuh Kambing Samosir Jantan dan Betina}

Persamaan ukuran dan bentuk tubuh Kambing Samosir berdasarkan analisis komponen utama (AKU) di Kecamatan Nainggolan Kabupaten Samosir disajikan pada Tabel 2.
Tabel 2 menunjukkan keragaman total komponen utama ke-1 (persamaan ukuran tubuh) yang disetarakan dengan ukuran pada ternak jantan dan betina secara berurutan adalah 64,5 dan 55,5. Keragaman total komponen utama ke-2 (persamaan bentuk tubuh) yang disetarakan dengan bentuk pada ternak jantan dan betina secara berurutan adalah 12,9 dan 15,5. Variabel 
ukuran tubuh ternak kambing Samosir jantan dan betina yang memiliki nilai terbesar adalah Panjang Badan (PB). Hasil penelitian ini berbeda dengan penelitian (Suryani et al., 2016) yang menyatakan bahwa penentu ukuran pada ternak Kambing Boerawa di kecamatan Sumberejo yaitu Lingkar Dada (LiD) dengan persentase 68,28. Hal ini diduga karena adanya perbedaan genetik, perbedaan tempat, dan sistem pemeliharaan. Hal ini sesuai dengan pendapat Gunawan et al., (2008) bahwa selain faktor genetik perbedaan ukuranukuran tubuh yang terjadi disebabkan perbedaan lingkungan diantaranya manajemen pemeliharaan. Analisis komponen utama Kambing Samosir jantan dan betina disajikan pada Gambar 1. Variabel bentuk tubuh kambing Samosir jantan dan betina yang berkorelasi positif dan terbesar yaitu Lebar Dada (LeD). Hasil penelitian ini sesuai dengan pendapat (Setiawan et al., 2017) yang menyatakan bahwa persamaan bentuk ternak kambing kacang jantan dan betina yang memiliki vector eigen tertinggi terdapat pada Lebar Dada (LeD). Nilai korelasi ini merupakan nilai korelasi paling tinggi diantara nilai korelasi antara skor bentuk dan variabel linear permukaan tubuh yang diamati artinya lebar dada merupakan penciri bentuk karena memiliki kontribusi terbesar terhadap persamaan bentuk. Berdasarkan uraian di atas dapat dinyatakan bahwa PB dapat dijadikan sebagai parameter seleksi untuk meningkatkan skor ukuran tubuh dan LeD dapat dijadikan sebagai parameter seleksi untuk meningkatkan skor bentuk tubuh kambing Samosir Kecamatan Nainggolan, Kabupaten Samosir, Provinsi Sumatera Utara.

Tabel 2. Karakteristik kuantitatif penentu penciri ukuran dan penciri bentuk tubuh kambing Samosir jantan dan betina. The quantitative characteristics of the determinants characterization of the size and body shape of male and female Samosir goat.

\begin{tabular}{|c|c|c|c|c|}
\hline $\begin{array}{c}\text { Jenis } \\
\text { kelamin } \\
\text { Gender } \\
\end{array}$ & & $\begin{array}{c}\text { Persamaan } \\
\text { Equation }\end{array}$ & $\begin{array}{c}\text { Keragaman Total } \\
\text { Total Diversity }(\%)\end{array}$ & $\Lambda$ \\
\hline \multirow[t]{2}{*}{ Jantan } & $\begin{array}{l}\text { Persamaan } \\
\text { Ukuran Tubuh }\end{array}$ & $\begin{aligned}= & \mathbf{0 , 4 4} \mathbf{P B}+0,371 \mathrm{TP}+0,363 \mathrm{LiD}+ \\
& 0,411 \mathrm{DaD}+0,235 \mathrm{LeD}+0,416 \\
& \mathrm{TPi}+0,373 \mathrm{LK}\end{aligned}$ & 64,5 & 4,51 \\
\hline & $\begin{array}{l}\text { Persamaan } \\
\text { Bentuk Tubuh }\end{array}$ & $\begin{aligned}= & 0,029 \mathrm{~PB}-0,085 \mathrm{TP}-0,109 \mathrm{LiD} \\
& +0,088 \mathrm{DaD}+\mathbf{0 , 8 8 4} \mathbf{L e D}-0,055 \\
& \mathrm{TPi}-0,434 \mathrm{LK}\end{aligned}$ & 12,9 & 0,90 \\
\hline \multirow[t]{2}{*}{ Betina } & $\begin{array}{l}\text { Persamaan } \\
\text { Ukuran Tubuh }\end{array}$ & $\begin{aligned}= & \mathbf{0 , 4 5 8} \mathbf{P B}+0,369 \mathrm{TP}+0,378 \mathrm{LiD} \\
& +0,388 \mathrm{DaD}+0,313 \mathrm{LeD}+0,254 \\
& \mathrm{TPi}+0,445 \mathrm{LK}\end{aligned}$ & 55,5 & 3,88 \\
\hline & $\begin{array}{l}\text { Persamaan } \\
\text { Bentuk Tubuh }\end{array}$ & $\begin{aligned}= & 0,133 \mathrm{~PB}-0,169 \mathrm{TP}-0,233 \mathrm{LiD} \\
& +0,155 \mathrm{DaD}+\mathbf{0 , 5 7 9} \mathbf{L e D}-0,731 \\
& \mathrm{TPi}+0,077 \mathrm{LK}\end{aligned}$ & 15,5 & 1,08 \\
\hline
\end{tabular}

Keterangan: $\mathrm{PB}=$ Panjang Badan/ Body Length, $\mathrm{TP}=$ Tinggi Pundak/ Shoulder Height, LiD = Lingkar Dada/Chest size, $\mathrm{DaD}=$ Dalam Dada/Chest Depth, LeD = Lebar Dada/Chest Width, TPi = Tinggi Pinggul/Hip Height, LK = Lingkar Scrotum/Scrotum circumference.
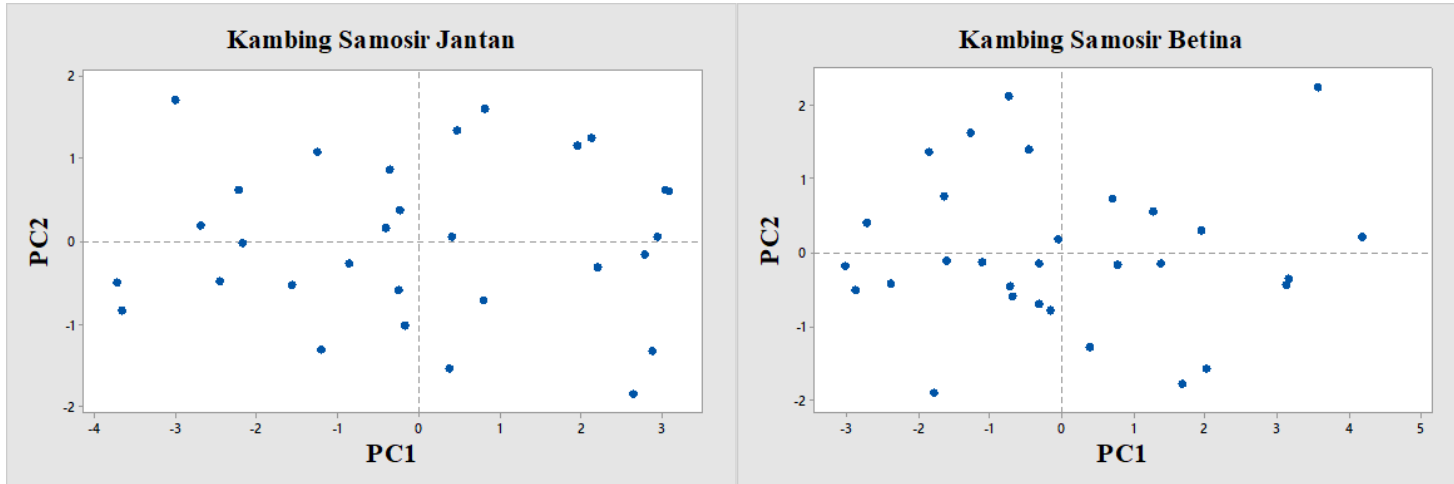

Gambar 1. Analisis komponen utama Kambing Samosir jantan dan betina. Analysis of the main components of male and female Samosir Goat 


\section{SIMPULAN}

Berdasarkan hasil dan pembahasan dapat disimpulkan bahwa bobot badan dan pertambahan bobot badan pada Kambing Samosir jantan lebih tinggi dibandingkan kambing Samosir betina. Faktor penentu ukuran tubuh adalah panjang badan sedangkan faktor penentu bentuk tubuh adalah lebar dada.

\section{DAFTAR PUSTAKA}

Gaspersz, V. 2006. Teknik Analisis dalam Penelitian Percobaan. Penerbit. Tarsito Bandung.

Ginting, R. H., A. Farajallah, D .P. Farajallah, dan A. Batubara. 2017. Variasi genetik gen myostatin ekson 3 pada sembilan bangsa kambing lokal di Indonesia. J. Ilmu Pertanian Indonesia, 22(2):73-78.

Gunawan, A.K. Jamal, dan C. Sumantri. 2008. Pendugaan bobot badan melalui analisis morfometrik dengan pendekatan regresi terbaik Best Subset pada domba garut tipe pedaging, tangkas dan persilangannya. Majalah Ilmiah Peternakan, 11(1):1-6.

Hanafi, N. D., M. Tafsin, R. Lumbangaol, dan R. E. Mirwandhono. 2017. Potensi produksi hijauan pada pastura alami di pulau Samosir kabupaten Samosir. J. Pertanian Tropik, 4(2):130-139.

Mardhianna, S. Dartosukarno, dan I.W.S. Dilaga. 2015. Hubungan antara ukuran-ukuran tubuh dengan bobot badan kambing jawarandu jantan berbagai kelompok umur di kabupaten blora. J. Animal Agriculture, 4(2):264-267.

Socheh, M., S.W. Purbojo, dan L.R. Hakim. 2018. Pengaruh bangsa sapi potong terhadap bobot potong, bobot karkas, dan persentase karkas. Prosiding Seminar Teknologi dan Agribisnis Peternakan VI: pengembangan sumber daya genetik ternak lokal menuju swasembada pangan hewani ASUH. Hal. 297-301.

Murdjito, G., I.G.S. Budisatria, N.N. Panjono, dan E. Baliarti. 2011. Kinerja kambing Bligon yang dipelihara peternak di desa Giri Sekar, Panggang, Gunung Kidul. J. Buletin Peternakan, 35(2): 86-95.

Nurfaizin, dan P.R. Matitaputty. 2017. Karakteristik sifat kuantitatif dan kualitatif kambing lokal di pulau Moa, provinsi Maluku. Prosiding Seminar Nasional Teknologi Peternakan dan Veteriner. Teknologi Peternakan dan Veteriner mendukung Kemandirian pangan di era industri 4.0. 15-17 Oktober. Hal. 322-328. Jember.

Putri, D.A. 2014. Pengaruh jenis kelamin terhadap perubahan dimensi tubuh ternak kambing kacang yang dipelihara secara intensif. Skripsi. Universitas Hasanuddin. Makasar.

Setiawan, Depison, dan Gushairiyanto. 2017. Analisis komponen utama sifat morfometrik kambing kacang pada dataran tinggi dan dataran rendah di Provinsi Jambi. Fakultas Peternakan Universitas Jambi. Jambi.

Setiyono, A.H.A. Kusuma, dan Rusman, 2017. Pengaruh bangsa, umur, jenis kelamin terhadap kualitas daging sapi potong di daerah istimewa yogyakarta. Buletin Peternakan, 41:176-186.

Soeparno. 2005. Ilmu dan Teknologi Daging. Cetakan ke-4. Gadjah Mada University Press. Yogyakarta.

Suryani, A.I., Sulastri, dan I. Harris. 2016. Perbedaan bobot dan ukuran tubuh kambing boerawa grade 1 umur satu tahun dari beberapa pejantan kambing Boer di Kecamatan Sumberejo. J. Ilmiah Peternakan Terpadu, 4(1):86-93. 